\title{
Recycling and Networking
}

\author{
T. Bányai
}

In recent years, the notion that for environmental and legislative reasons improvements The national environmental policies and practice, including recycling strategies, are desirable and in many cases might be economically beneficial has been gaining ground. Although according to recent surveys the state of the environment in Hungary is in line with average values of the European Union, the main challenge for the country is to achieve sustainability in economic, environmental and technological terms. With a view to accession to the European Union, a harmonisation strategy must be worked out and implemented. This harmonisation strategy includes not only legislative aspects, but also social, technological, financial and logistic considerations.

Because of the high logistic costs of achieving closed loop recycling systems, the author focuses on logistic aspects and tasks of the improvement phases and concentrates on the possibilities of networking and co-operation. The paper describes some possible alternative solutions for co-operative recycling processes, to improve the following logistic parameters: delivery times, accuracy of supply, running times, utilization of capacities, stock quantities, flexibility, transparency of the system, high forwarding capability, quality of product. The logistic aspects of co-operation will be analysed from the viewpoint of a closed loop economy.

Keywords: co-operation, logistics, networking, optimisation, recycling.

\section{Introduction}

Ensuring people's quality of life within the means of nature involves many responsibilities for present-day society. Strategies for environmental protection and recycling of used appliances, industrial and communal wastes are helpful in order to create a closed loop economy. In recent years, the notion has been gaining ground that, for environmental and legislative reasons, improvements in national environmental policies and practice, including recycling strategies, are desirable and in many cases may be economically beneficial. Globalisation and the reduction of the life cycle of products, technologies and services have led to an increase in competition among enterprises in the field of recycling [1]. Individual enterprises are no longer able to respond to the changing market needs and recycling activities because of their outdated organisational structures. In this way, the role of co-operating forms has been rising, because they can achieve economic and technologic advantages that which companies working separately could not achieve on their own. Within the frame work of this paper, the author will present the main logistic tasks and the design conception for cooperative recycling processes to improve the existing closed loop economy of future EU member states like Hungary [2].

A precise definition of these logistic tasks and the elaboration of an execution plan is important for the new EU member states, and thus for Hungary, because in a short time after accession a system has to be in action that meets the EU norms, the technological, logistic, economic, legal, political and social conditions.

\section{State of the art vs. EU practice}

Nowadays the governments of the OECD states definitely consider the environment as a strategic sector. This thought involves mot only ecological aspects it is also important that the environment has become a major economic and market factor, and several enterprises owe their success to their environmental approach. In the OECD states, general environment - oriented services account for nearly one quarter of the total industrial output, mainly in the form of engineering and consultative services: process planning, reg- ulation planning, project management, influence tests, environment surveys, environment monitoring, risk management, expert systems, financial analysis, and database administration [3].

The governments of the CEE countries should do their best into bring their laws, economy and regulations in line with EU directives and regulations. Hot areas are environmental protection, the development of environmental awareness, the development of an environmental industry, waste management, the application of clean technologies, closed loop production, and the introduction of environment control systems in companies [4], [5].

Collection, take-back and recycling of used household appliances have been under discussion in Europe for many years. The main reasons for addressing this subject are as follows: reduction of waste volume, promoting the recycling of materials, closing the loop, use of fewer resource, better control over toxic substances, reducing environmental risks $[6]$.

The recycling of products is also dealt with by international agreements:

- the Rio de Janeiro Conference, which stated that "the natural load is not restricted and we do not pay enough",

- BS (British Standard) amendment 7750,

- EMAS Environmental Management and Audit System,

- the introduction of ISO 14000 in environmental auditing,

- the Basel Convention on the qualification and export of waste in Europe, the recommendation of the 'polluter pays' principle.

Although the objective of the Act on Environmental Product Fees and on the Environmental Product Fees of Individual Products (Act LVI of 1995) is to create financial resources for the reduction and prevention of damage to the environment or one of its elements caused by the production or the use of a product or directly or indirectly imposing harm or stress on the environment as a consequence of the consumption of a product, and replace pollution of the environment and stimulate economic management of natural resources, the Hungarian directives need to be harmonised with the directives of the European Union. 
The European Union has decided that improving the closed loop economy is the most important step in the field of equipment containing hazardous materials, like electric and electronic equipment. The European Parliament and the Council have made proposals for directives on electric and electronic equipment wastes. On the basis of these directives, the milestones for possible future improvement are the following: treatment, selective collection, recovery, financing in terms of WEEE, information for users, information for treatment facilities, information requirements, reporting obligation and adaptation to scientific and technical progress [7].

\section{General collection structures of recycling}

The first and principal step in forming a potential recycling collection system structure is to explore the potential system elements. Although two main types of recycling technology exist (disassembly and shredding), based on previous Hungarian experience we can say that the future recycling system will basically depend on disassembly technology. The target during the formation of the recycling system is to form of a logistic system, that is capable of collecting used electronic products from the end users in an economical manner and setting them to disassembly plants [8], [9].

The number of disassembly plants can be determined according to the required disassembly capacity. When determining the number of disassembly plants, the basic question is whether one large plant is to be set up on one site, or several plants with smaller capacity on a number of sites. It is important to determine the types of products to be disassembled by a plant (homogeneous, inhomogeneous or mixed disassembly). Determining the range of products to be disassembled, at the plant is a very important strategic decision, like the determining the range of products drawn into the orbit of the collection process, since it will define the companies working in strategic co-operation in the collection and recycling system. Currently there is one disassembly plant in Hungary that can be used to disassemble discarded refrigerators, freezers and freezing boxes. Thus the number of disassembly plants and the types of products that can be linked to them is still an open question, especially because there is still no kind of agreement among the Hungarian companies that make electronic household appliances about a collecting-disassembly system which can be operated in co-operation. However, on every account, the future foreshadows the formation of an all-round co-operating system, because establishing and operating several collecting-disassembling systems does not seem practical in a small country.

A collection system can basically comprise the following elements: end users, waste courts, stores, services, distributors [10]. Using these elements, a single or multilevel logistic collection system has to be formed, which, taking into account the characteristics of the above listed elements, offers the users and recyclers an economical way to collect discarded products. End users can be communal users and private users. It is important to distinguish between them during the formation of the collection system. While in the case of private users a single item is usually collected, in the case of communal users a larger quantity is usually collected from each communal unit. Thus it would be useful in the collection system to deliver the used products of private and communal users to different collection points. When determining the number of collection levels, two important target functions

Number of disasem bly plant
Number of collection levels
Characteristic of end users
Intermediary collection places
W aste court
Distributor
Store
Service

Mobil collection

Pre-disassembly

Homogeneity of products

Homogeneity of collection

Homogeneity of processing

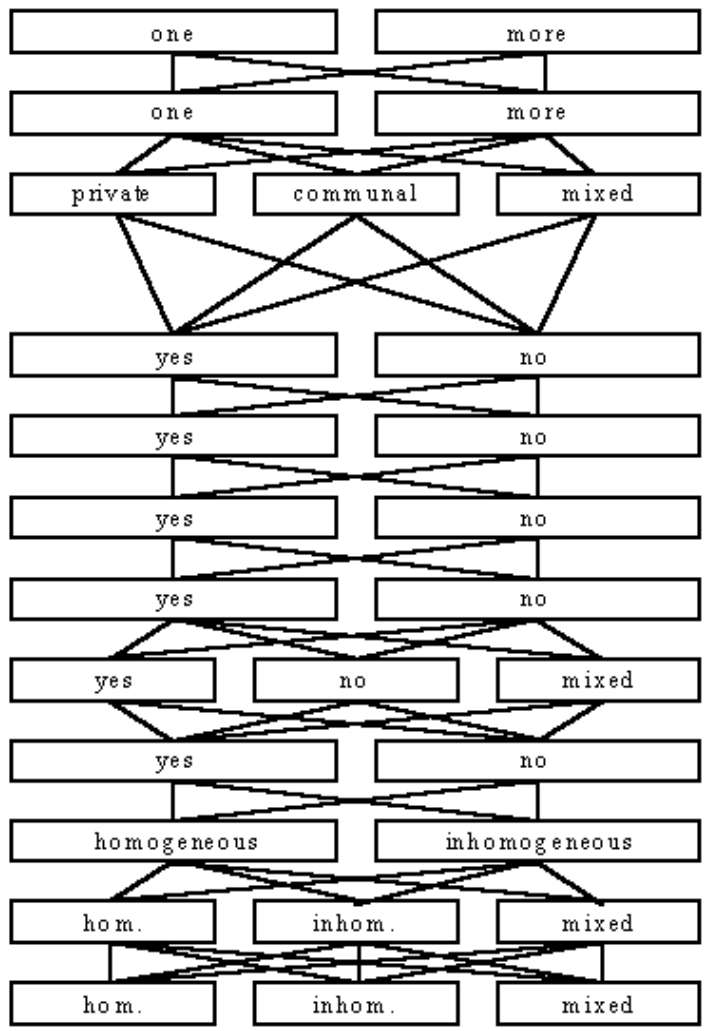

Fig. 1: Structure of collection systems 
have to be considered. One target function is to minimize the implementation costs, which can be achieved by reducing the number of collection points. The other target function is to minimize the delivery costs linked to the operation of the collection system, which can be achieved by increasing the number of collection levels and collection points.

When electronic household product began to be recycled (in about 1993), mobile as well as stationary disassembly plants were analysed, but for economic and geographical reasons, the planning and partial realization of versions of the collecting system were based on stationary disassembly plants. Pre-disassembly is especially important in the case of products of this kind, when the volume of large items can be reduced in the early phase of collection. However the applicability of pre-disassembly has to be investigated carefully from the economic viewpoint because implementation and operation of a pre-disassembly plant considerably increase the operation and maintenance costs. Figure 1 shows the general structure of the logistic collection system, from which the characteristic system versions can be derived.

As shown in Fig. 1, the logistic collection system consists of a number of participants; therefore such a system can be operated only in the form of co-operation. The next section will introduce forms of co-operation in the framework of which these collection and recycling systems can be operated.

\section{Networking possibilities of recycling}

Operation of the recycling system can be done in two co-operation forms. One is the virtual enterprise, and the other is the cluster. A virtual enterprise is a temporary network of companies that come together rapidly to exploit fast changing opportunities. In a virtual enterprise, companies can share costs, skills and access to global markets, with each partner contributing what it is best at. This network is based on economic relationships, which can be flexibly built or broken up depending on demand. The most important partners of a general virtual enterprise can be purchasers, producers, distributors and end users [11, 12, 13, 14, 15, 16].

Forming a cluster is a process that may start with an initial natural advantage or chance use of a location, leading to collaboration among several firms, present-day official OECD and EU definition of a cluster is as follows: the abilities of companies, industries, regions, nations and regions above nations to produce relatively high income beside relatively high employment while they are in international competition. Advantages of co-operation based on geographical concentration and reliance: low transaction costs (communication), low transport costs, opportunities for special services, face-to-face communication, comparatively simple feasibility of JIT conception, cost reduction because of common quality assurance, etc. Since Hungary is not a large country, thus the co-operation forms operating in it can be classified as cluster type co-operation.

Co-operation type operating forms can be successfully applied in two important fields of collection and recycling systems. These are harmonized operation of a) the collection system and b) the disassembly plants. The virtuality of the collection system means that the potential participants in the collection system (end users, waste courts, stores, services, distributors) do not in a legal sense operate in a common organization, but their operation is harmonized by a virtual logistic centre. The virtual disassembly system, which ensures the co-operation of plants specialized in disassembling various product groups, can work on the same principle. Obviously, the co-operation between the collection system, the disassembly system and the distribution-recycle system is

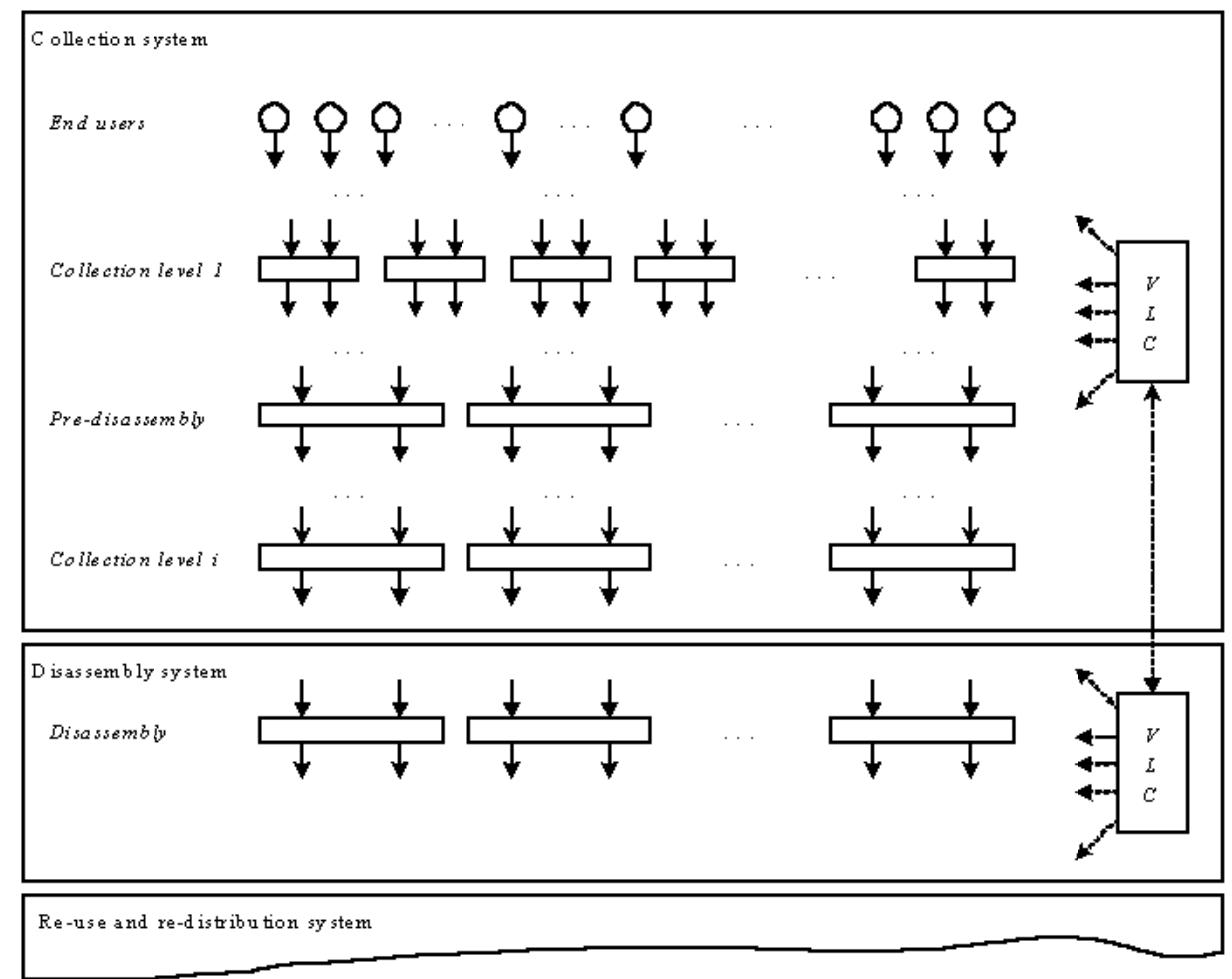

Fig. 2: Co-operative subsystems of the recycling process 
essential. This high level co-operation is basically carried out by communication among the virtual logistic centres operating the individual sub-systems, but it is also possible for one virtual logistic centre to ensure the harmonized operation of the whole sub-system (see figure 2). Obviously, the virtual logistic centres do not onlydeal with harmonizing the technological and logistic processes, but they also have to keep in contact with the partners concerning the whole business process (banking, exchange, insurance, dealing with the authorities, ministries, external services, etc.)

In Hungary, because of its small size, it seems practical to operate the whole system by a single logistic centre, but the final number of logistic centres and the structure of the system can be determined only after performing quantitative and qualitative analyses of the products to be collected and recycled, taking into account technology, logistics and economics, and the result can be considered as a long-term strategic decision from the point of view of the cooperating partners.

\section{Conception of the design of collection systems}

When an optimal logistic collection system is being formed, the internal and external logistic aspects need to be considered. External logistic aspects are basically connected with the collection processes: products to be collected and recycled, the topology of the collection/distribution system, hierarchical and heterarchical characteristics, collection/distribution routes, route planning, planning of storage, choosing transport and loading devices, scheduling of supply/distribution. Internal logistic have to receive due considering when the disassembly system is being designed: topology of the disassembly systems, topology of the disassembly plants, choice of material handling devices, planning of stores of used products and reusable components/materials, scheduling of disassembly, pre-disassembly possibilities [17].

The first task during the formation of the logistic collection system is to determine the product group to be collected and the quantitative and qualitative parameters of these products. While the European Union directives specify the quantity to be collected as $4 \mathrm{~kg} /$ person, the quantity related to a company can be determined by market participation. For this, the first step is to make a long-term trend analysis considering the marketing results of the previous period. In this trend analysis it is practical, based on the regression method, to determine the marketing trend of each product, because the marketing trend of a product that has already been in the market is determined differently than in the case of a new product in the market. For example, in Hungary the market for built - in ovens and cookers is quite small, but dynamic growth is expected, so it is practical to apply an exponential or logistic function. Meanwhile, in the case of products that have been already been in the market for a long time, linear regression methods are applicable. Based on the values estimated this way, the future market share and the quantity to be collected can be calculated. The recommended next step in the quantitative analysis is to determine the quantity of products to be collected according to region. When the quantity distribution in the regions is estimated, not only the population but also the standard of living has to be considered, for example taking into account the GDP or unemployment ratio as a weighting factor. Based on this distribution, the parameters of the required collection structure can be determined.

The aim of qualitative analysis is to determine the distribution of the products to be collected in order of age. For this, an amortization function needs to be used (see Fig. 3), which defines how much of a given type of product becomes waste as function of its age [18]. This amortization function may differ for different products, as a function of the product life-cycle graph.

When the quantitative and qualitative parameters are known, the collection system can be planned, which basically means selection based on a comparative analysis of the optimized system versions. During the formation of system versions, analysis of single- and multilevel collection systems is recommended, taking into account different region forming methods and disassembly system structures. A typical system version can be as follows: a single-level collection system with one or more disassembly plant, a multi-level collection system with one or more disassembly plant.

Although the investment costs are relatively low in the case of a single-level, single-disassembly placed collection system (see Fig. 4), the operation costs will be high, since the customers will have to transport their waste products over large distances. In this system, private users as well as communal users take their products to the same collection system. In the case of Hungary, this system version requires the formation of 18-20 collection centres, if each country has a collection centre, and the customers have to transport their waste products an average distance of $30 \mathrm{~km}$. When forming the collection

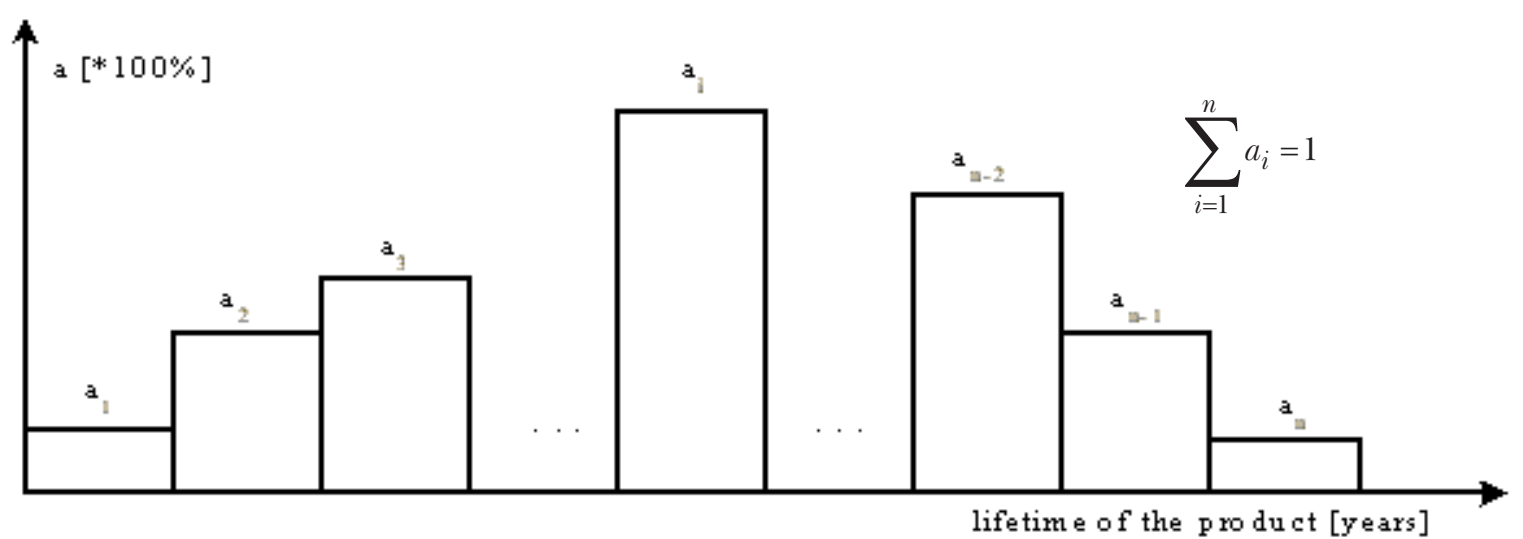

Fig. 3: Amortization rates 


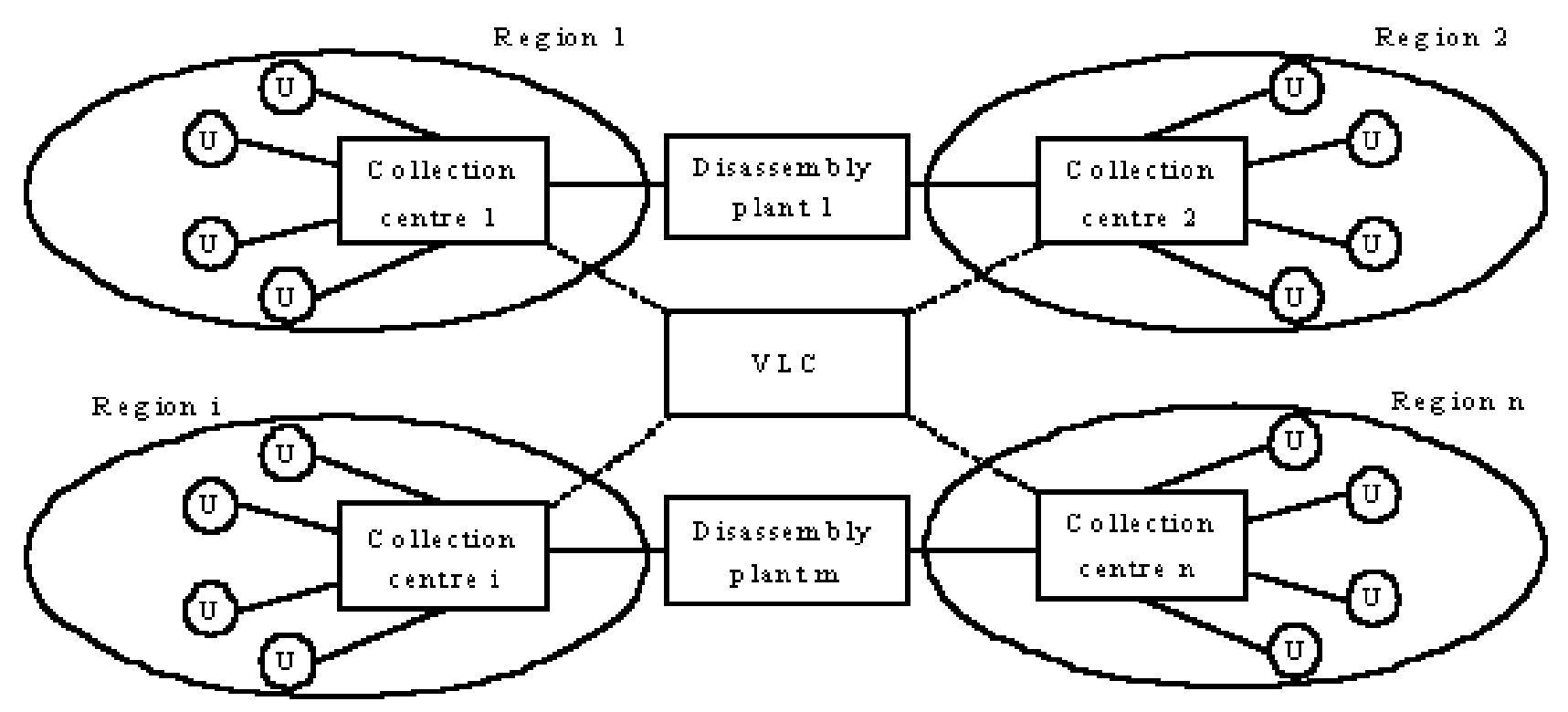

Fig. 4: Single-level collection system

system, it is recommended to consider having regional collection centres at institutions that already exist or will be established obligatorily during connection to EU systems. If the tasks of the collection centres are carried out by waste courts, the regulations of the operations of waste courts have to be modified in a way that will enable large amounts (from communal users) of dangerous wastes to be accepted.

According to the current executive decree (98/2001 executive decree $12 \S$ ) a waste collection court can be operated in order to collect dangerous wastes originating in small amounts from households or from other sources. The operator of the waste collection court is allowed to receive a small amount of dangerous waste that does not originate from household sources by agreement with the owner of the waste. The owner of the waste can use the waste collection court for collection only if the quantity of dangerous waste originating from him in the course of a year is not more than $500 \mathrm{~kg}$. The operator of the waste collection court has to pass the collected dangerous waste over to a licensed waste treatment body. Dangerous wastes may not be kept in the waste collection court longer than 1 year from the date of receipt. It is not necessary to lift the ban on storage longer than 1 year in the case of a collection system that functions with a well-operating disassembly plant that has the required disassembly capacity. However, in the case of communal users the upper limit of $500 \mathrm{~kg}$ is not acceptable. Naturally if these modifications cannot be carried out, the establishment of a new institution is required. In the case of the single-level collection system shown in Fig. 5, the collection and disassembly processes are harmonized by a single virtual logistic centre. Although the investment costs are relatively high in the case of a multi level collection system, the operation costs will be quite low, since the customers have to transport their waste products over only short distances.

Although the investment costs are considerable in the case of a the multilevel collection system, because the extra collection levels include building up quite a large number of collection points, it is obviously a comfortable solution for the end users because they have to deliver their used products over only short distances $[19,20]$. However, to type of a collection system shown in Fig. 5 can be also built up by using plants or plant networks already in operation, because low investment costs can make the product distribution network capable of doing the tasks of an element of the collection system. The collection points can be department stores, servicing stations, distributors, while the collection centres can be working waste courts or other plants. A distinction needs to be made between private and communal users in this collection system, because the receivable quantities are limited at the collection points due to the limited logistic capacities. It therefore seems logical to link the communal users directly to the collection centres. The system shown in Fig. 5 consists of two virtual logistic centres, which harmonize the operation of the two large subsystems.

The need for co-operation is visible in the case of these two systems. The tasks of the virtual logistic centres basically involve harmonizing the collection process and the disassembly process in order to minimize delivery times, increase the accuracy of the supply process, minimize running times, increase the utilization of resources (human, technology and logistics), decrease the stock quantities, increase the flexibility of the whole system, and increase the forwarding capability.

If the target function during the formation of the collection system is to minimize the performance and the inherent costs of materials handling, then we also have to consider the optimum formation of the collection runs, especially during the formation of collection levels near to the end user.

It is expedient to form a collection structure in which delivery tasks close to the end user are done by collection routes, and delivery tasks going into the disassembly system can be done by direct routes.

When forming the logistic system for collection, another important task is to determine the storage capacities in adition to the delivery capacities. The quantitative and time distribution of the used products to be stored is highly stochastic at the collection level near to the end user. Since it is 


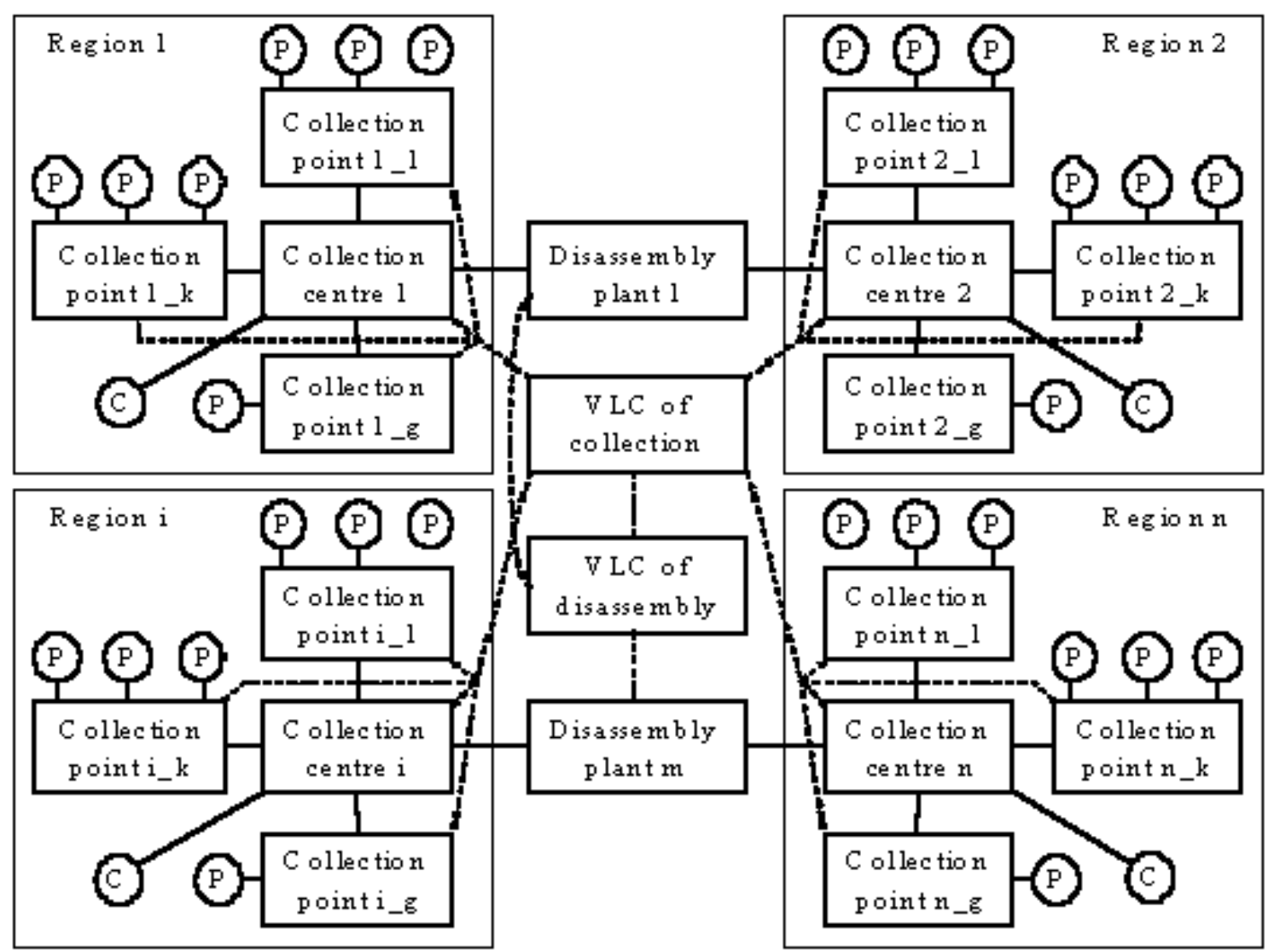

Fig. 5: Multi-level collection system

generally a matter of storing quantities for a short time at the level near to the end user, the above mentioned low calculability does not involve planning a storage capacity for large stores according to indefinite data. It involves storage places with small storage capacity built up at distributors and in waste courts. At the collection level near to the disassembly plants, large quantities are stored, and the stochastic characteristics of its quantities estimated by quantitative and qualitative analysis are smaller. The development of stocks with time can also be better estimated, because the deliveries are in phase with the production scheduling of the disassembly plants.

Waste management is a big business in Western Europe, where private and public stakeholders are involved. Therefore, much information is given by special systems such as official national statistics and required documentation or proof. In the new EU member states, effective waste management is either lacking or still in an early stage of development. Information systems, such as official national statistics and required documentation or proof, are not sufficiently available and need to be developed.

In order to bring about a closed loop economy quickly and efficiently, an appropriate legal background has to be formed as soon as possible, because the establishment of such by 2005 in the new EU member countries of a recycling system, that is economically, technologically, logistically and environmentally suitable and leads to a better style of living for those living in the common Europe depends on it.

\section{Conclusion}

Strategies for environmental protection and recycling of used appliances, industrial and communal wastes are helpful in order to create a closed loop economy. During the implementation of a closed loop economy not only the economic and technological aspects have to be considered, but also the logistic aspects, because a considerable part of the costs of a closed loop economy are the costs of logistic processes. Since harmonized co-operation among many economic participants is required during the realization of a closed loop economy, such co-operation is economically best implemented in the form of a network. In the case of Hungary, because of its small size, co-operation can be realized in the future in the form of clusters and virtual companies. In order to improve the standards of services in the collection system, it would be practical to form a multi-level collection system, although the costs of forming and operating a large number of institutions can be higher than the costs of a single level collection system. Forming a multilevel collection system requires considerable coordination, because of the many co-operating partners. This can be establishing a suitable informatic system.

\section{Acknowledgment}

This paper is based on work supported by a Bolyai János Scholarship from the Hungarian Academy of Sciences and the Hungarian Scientific Research Fund (Project number: F037525). Any opinions, findings and conclusions or recom- 
mendations expressed in this material are those of the author and do not necessarily reflect the views of the Hungarian Academy of Sciences. This research work is a part of the project of the Applied Co-operation Research Centre of Mechatronics and Material Science at the University of Miskolc entitled "Development of take-back system of end of life household appliances from the point of view of EU directives".

\section{References}

[1] Enright M. J.: Enhancing the Competitiveness of SMEs in the Global Economy, Strategies and Policies. in: Proceedings of the Conference for Ministers Responsible for SMEs and Industry Ministers, Bologna, 2000, p. 38.

[2] Bányai T.: Environmental improvement from the point of view if EU practice - closed loop economy, A Publication of the University of Miskolc, 1, 2003, p. 155-162.

[3] Hungary - Environmental Performance Review (2000), Conclusions and Recommendations.

[4] Hungary's EU integration website. (2002). http://www.mfa.gov.hu/euint/ index.html.

[5] Regular Report on Hungary's Progress towards Accession. (2002). http://www.mfa.gov.hu/euint/ index.html.

[6] Proposal for a Directive of the European Parliament and of the Council on Waste Electrical and Electronic Equipment (2000).

[7] Frentz W.: Kreislaufwirtschafts- und Abfallgesetz. Heymanns Verlag, 1996.

[8] Haase H., Gerecke A.: "Logistische Gestaltungsgrundsätze beim Einsatz von integrierter Sammelfahrzeugtechnik". In: Müll und Abfall. Vol. 12, 2000, p. 718-725.

[9] Haase H.: "Logistische Aufgabenstellungen im Spannungsfeld der Kreislaufwirtschaft”. In: Logistikeffekte in der Kreislaufwirtschaft. Magdeburger Schriften zur Logistik, Vol. 1, 1999.

[10] Sodtke M. W.: Redistribution Vertrieb und Umweltschutz. Entwicklung von Strategien und Maßnahmen zur Rückführung von Altprodukten auf der Grundlage der Produktdistribution. Tectum Verlag, 1997.

[11] Bányai Á.: "Das virtuelle Logistikzentrum als Koordinator der logistischen Aufgaben”. In: Modelling and optimization of logistic systems (Editors: Bányai T. and Cselényi, J.), University of Miskolc, 1999, p. 42-50.

[12] Bányai T.: "Logistic Analysis of Lifecycle of Virtual Enterprises". In: Proceedings of the XVII. International Conference on Material Flow, Machines and Devices in Industry (Editor: Tosic S. B.), University of Belgrade, 2002, p. 3.1-3.5.
[13] Filos E., Ouzounis V.: "Virtual Organisations: technologies, trends, standards and the Contribution of the European RTD Programme”. International Journal of Computer Applications in Technology, Special Issue: Applications in Industry of Product and Process Modelling Using Standards "Virtual-organisation.net", "Newsletter", Vol. 1, 1997, No. 3-4.

[14] Gesmann-Nuissl D.: "Virtuelle Unternehmens-organisation - eine gesellschafts- und kartell-rechtliche Betrachtung”. In: Virtuelle Organisationen im Zeitalter von E-Business und E-Government, Einblicke und Ausblicke (Editors: Gora W. and Bauer H.), Springer-Verlag, Berlin, 2001, p. 43-58.

[15] Karnani F.: "Virtuelle Wertschöpfungskette - mit revolutionären Strategiekonzepte die Märkte erobern". In: Virtuelle Organisationen im Zeitalter von E-Business und E-Government, Einblicke und Ausblicke (Editors: Gora W. and Bauer H.), Springer-Verlag, Berlin, 2001, p. 95-104.

[16] Sydow J., Winand U.: "Unternehmensvernetzung und -virtualisierung: Die Zukunft unternehmerischer Partnerschaften”. In: Unternehmensnetzwerke und virtuelle Organisationen, Schäffer-Poeschel, 1998, p. 11-31.

[17] Cselényi J. et al: "Recycling logistics as a new field of research of logistics". Economy, Culture and Science of North-Hungary, Vol. 5, 1996, No. 7-8, p. 19-26.

[18] Wallau F.: Kreislaufwirtschaftssystem Altauto. Eine empirische Analyse der Akteure und Märkte der Altautoverwertung in Deutschland. Deutscher Universitäts-Verlag, 2001.

[19] Bányai T. et al: Development of multi-level collection system of used household appliances. Report ACRC-MMS. Applied Co-operation Research Centre of Mechatronics and Material Sciences at the University of Miskolc, 2003, p. 32.

[20] Horváth E., Cselényi J.: "Der Wahl des optimalen Sammlungsmittels im Falle der integrierten mehrstufigen Abfallsammlung”. In: Modelling and optimization of logistic systems (Editors: Bányai T. and Cselényi J.), University of Miskolc, 1999, p. 42-50.

Tamás Bányai Ph.D.

phone: (36)(46)565111

fax: (36)(46) 563399

e-mail: alttamas@gold.uni-miskolc.hu

Department of Materials Handling and Logistics

University of Miskolc

Miskolc-Egyetemváros H-3515 